\title{
Coastal Online Analysis and Synthesis Tool 2.0
}

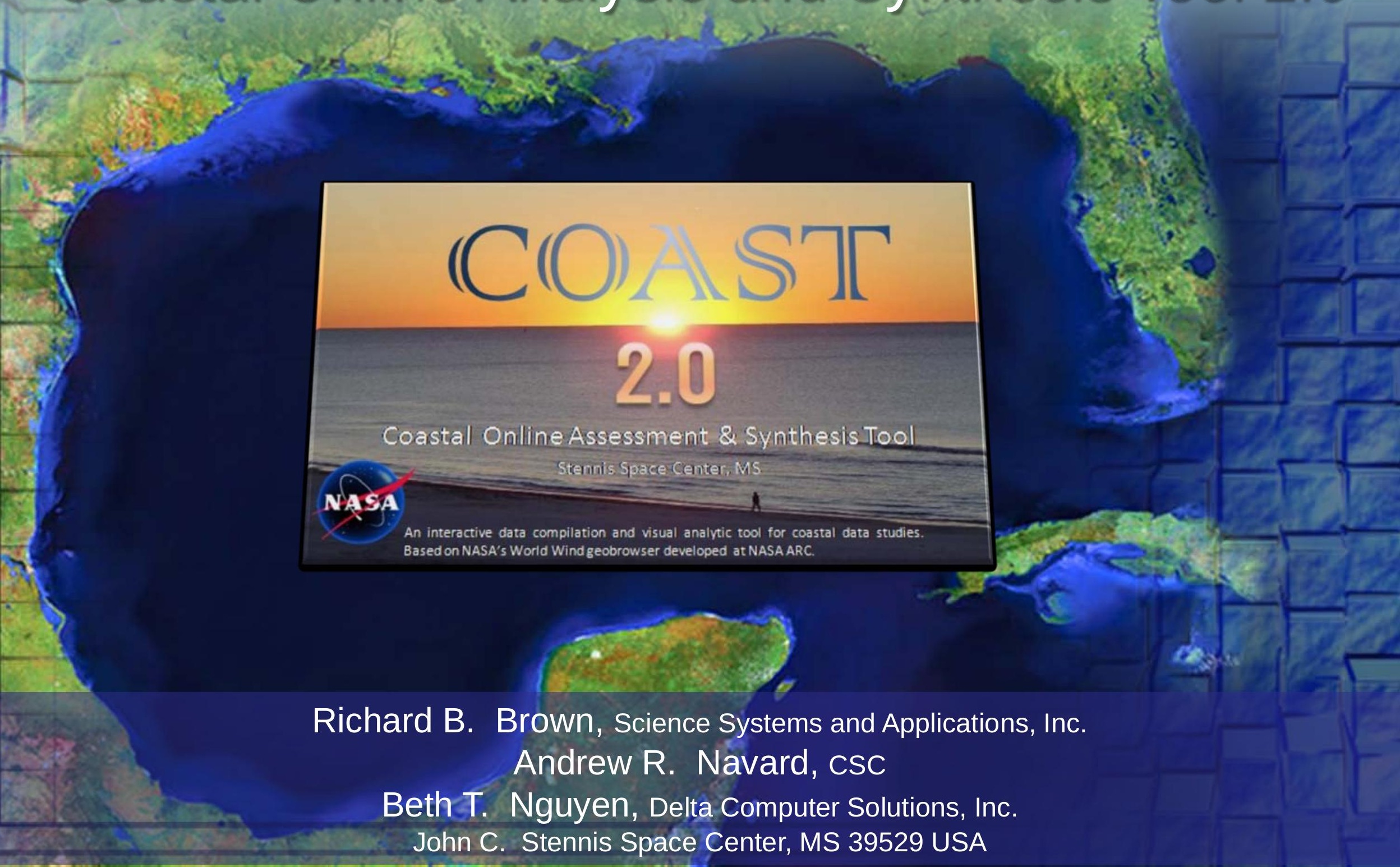


The Coastal Online Assessment and Synthesis Tool (COAST) 3D geobrowser has been developed to integrate disparate coastal datasets from NASA and other sources into a desktop tool that provides new data visualization and analysis capabilities for coastal researchers, managers, and residents.

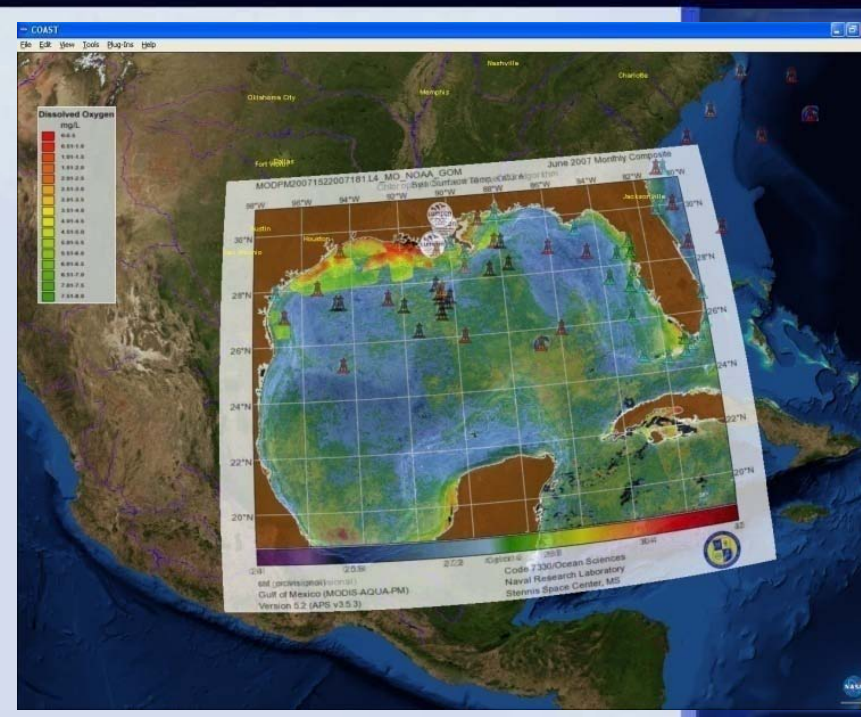

- Built upon the widely used NASA-developed open source World Wind geobrowser from NASA Ames (Patrick Hogan et al.)

- .Net and C\# version used for development

- Leveraged off of World Wind community shared code samples

- COAST 2.0 enhancement direction based on Coastal science community feedback and needs assessment (GOMA)

Main objective: empower user to bring more user-meaningful data into multi-layered, multi-temporal spatial context 


\section{World Wind}

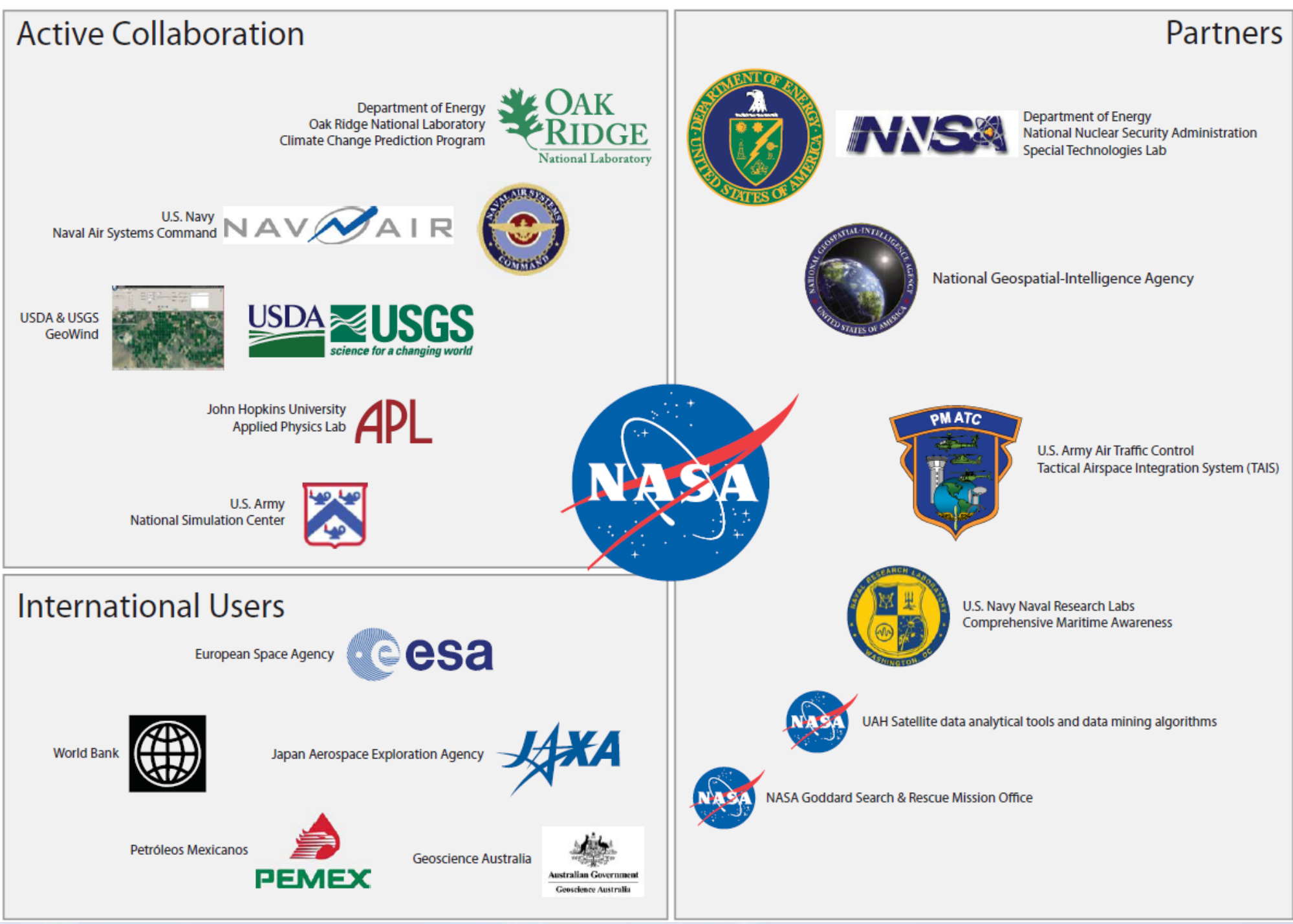

Coordinating with NASA Ames on WW

Integration (some contributing partners soon)

Funding World Wind Development 
- Temporal Visualization Tool enhancements for file input and animation

- RECORD-DM tool enhancements for local and FTP directory mapping

- Import Data Tool ${ }^{1}$ - Simpler, more powerful

- Add Points Tool $^{2}$ - Import or digitize point data

${ }^{1}$ Modified from elements of Image Overlay plugin by Bjorn Reppen

2 Modified from Favorite Icons plugin by D. Hill, C. Zimmerman, J. Zoehrer 
- Added local and FTP search capability to RECORD-DM data mapping tool

- Added load local file capability to TVT

- Allows creation and sharing of TVT temporal image playback files

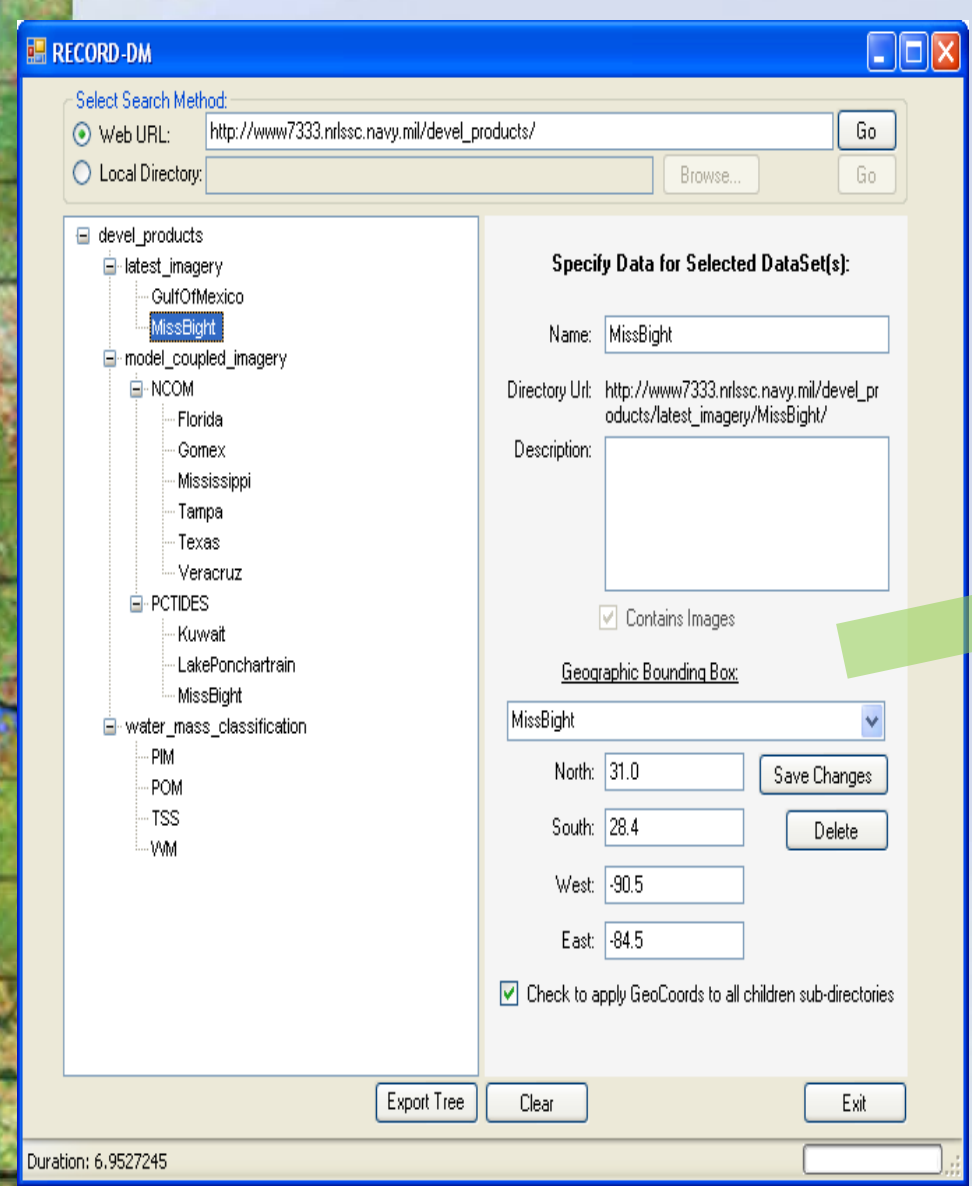

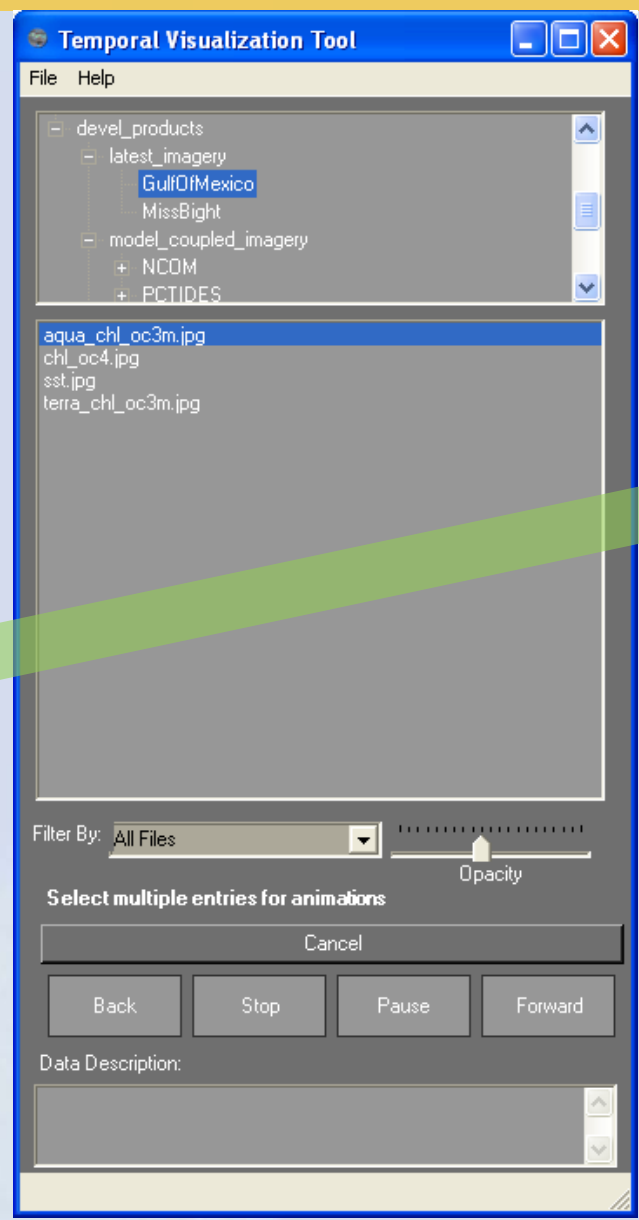

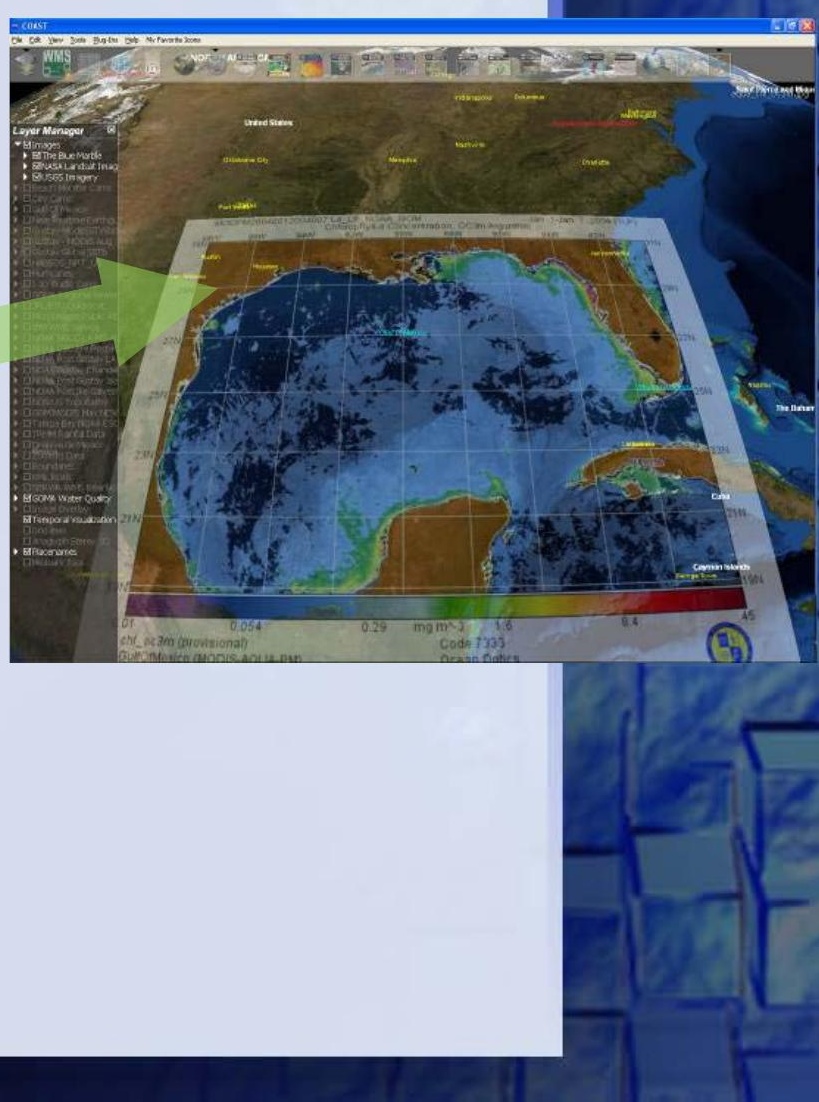


- Added local and FTP search capability to RECORD-DM data mapping tool

- Added load local file capability to TVT

- Allows creation and sharing of TVT temporal image playback files

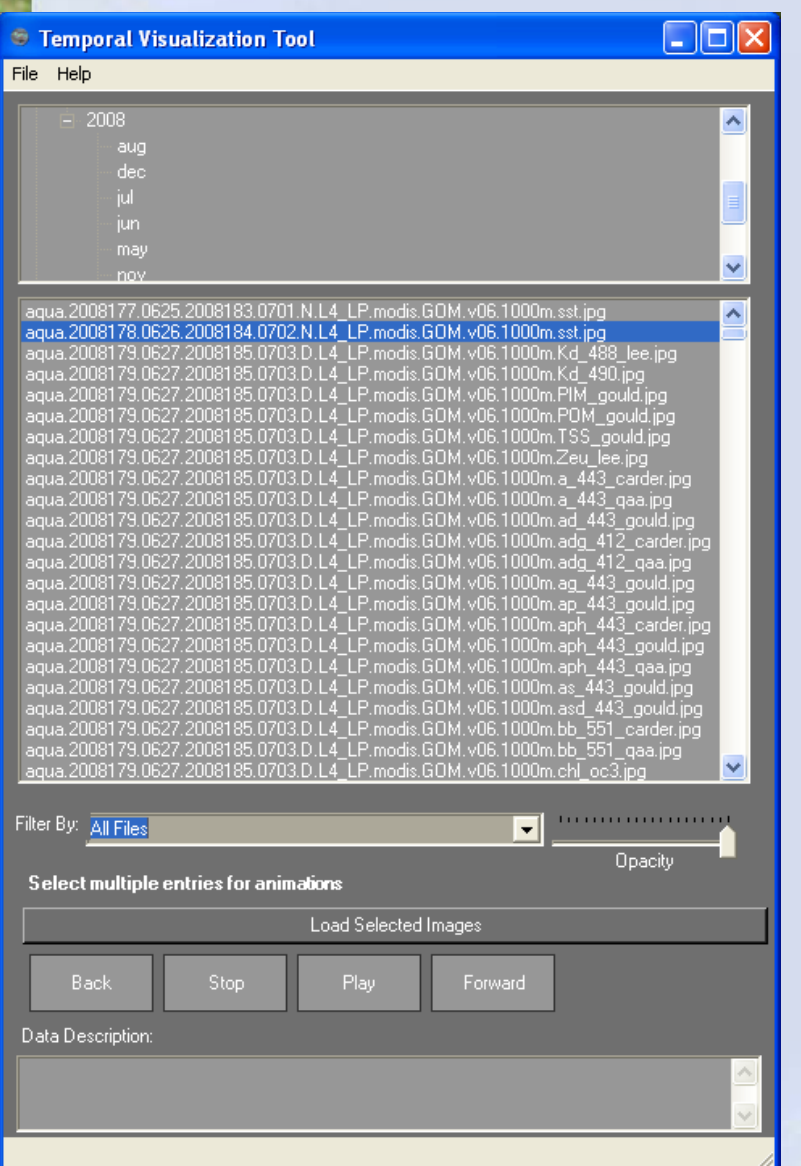

- Directory tree listing for selection

- "Filter by" common coastal science data types

- VCR-style controls for freeze frame review

- Current frame file name listed at top of screen

- Load other directory tree definition files through file menu

- User allowed to multi-select and sequential animate

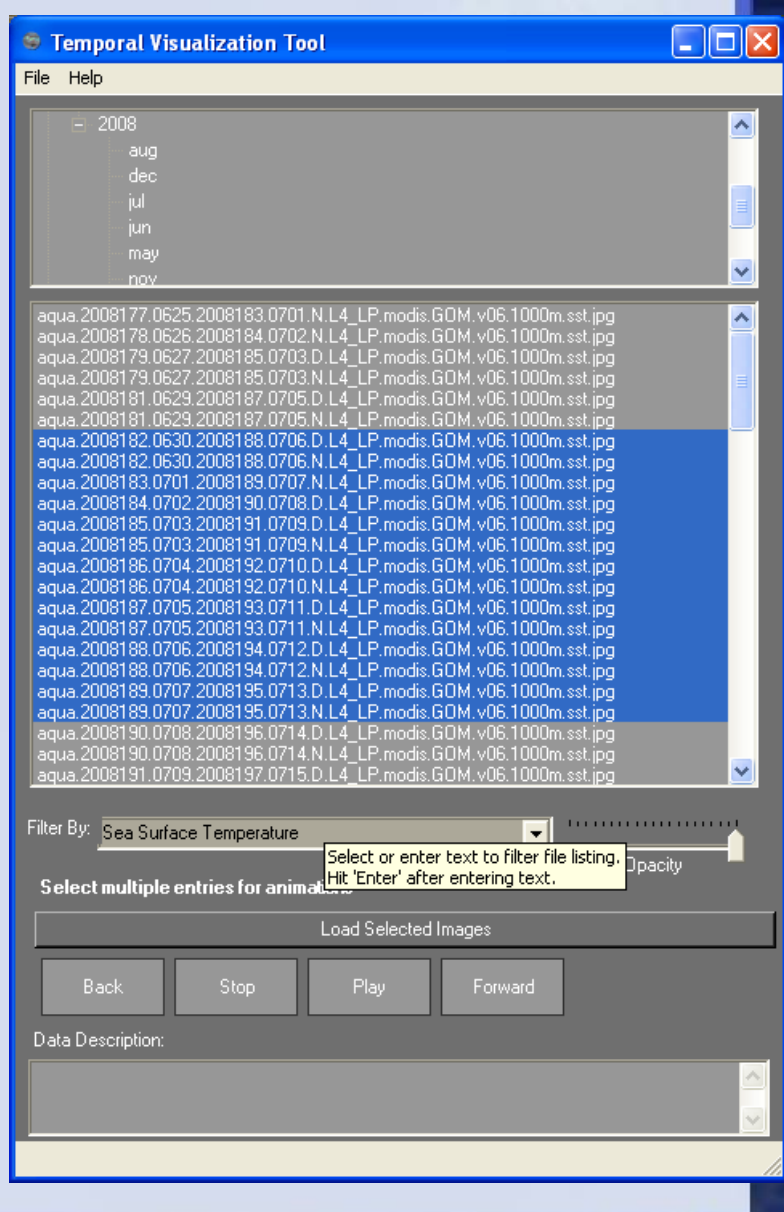



Recursive Online Remote Directory-Data Mapper/Temporal Visualization Tool
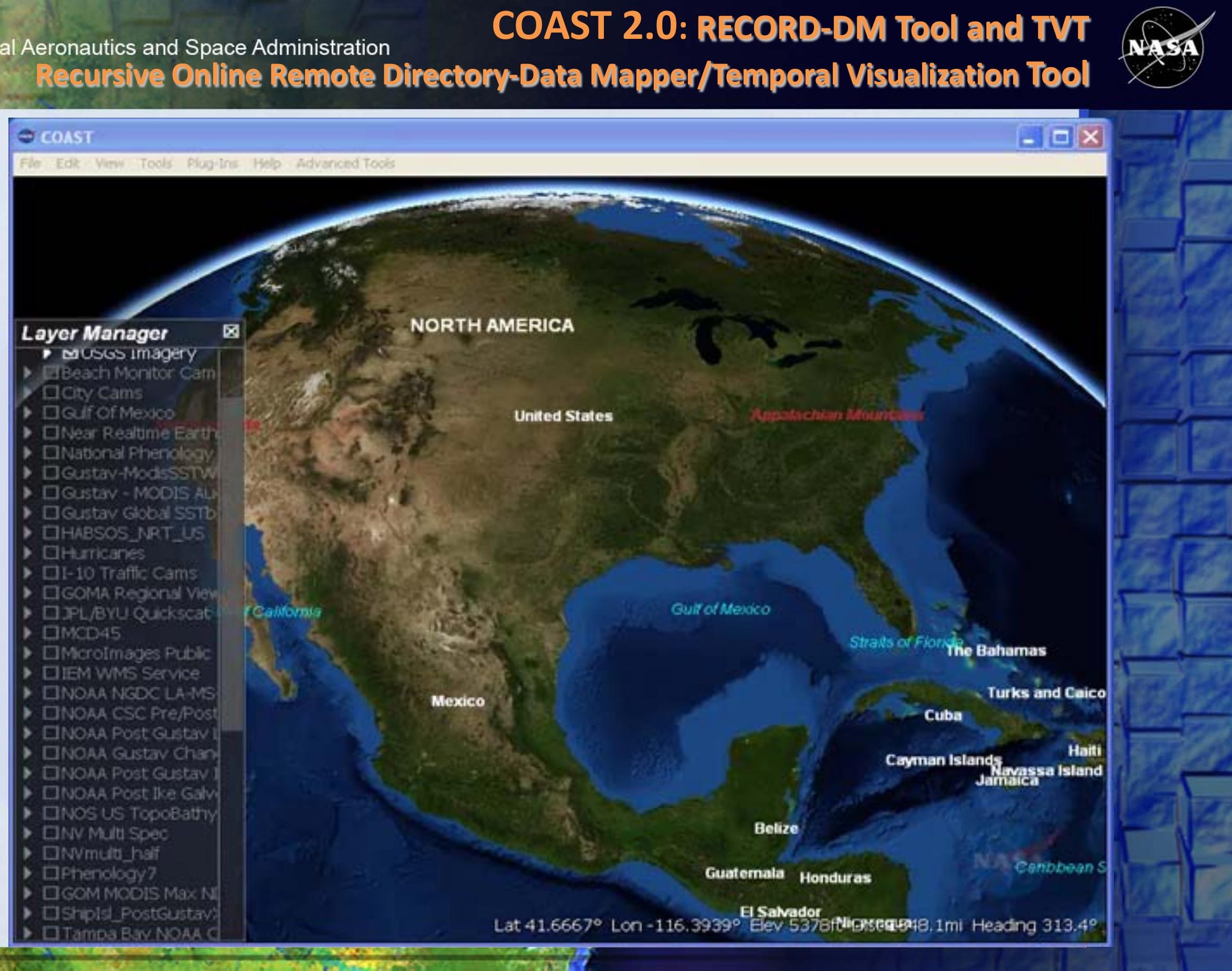


\section{COAST 2.0: Import Data Tool}

\section{Import Data Tool:}

\section{Interface Integration}

- Combining some elements of previous Image Overlay ${ }^{1}$, Shapefile Import ${ }^{2}$, and Layer save/creation ${ }^{3}$ plugins

- Will allow users more simplified ability for localized/personalized data integration and sharing

- Capability to import TIF, PNG, JPG, GIF with or without world file

- Rubber sheet placement of non-georeferenced imagery enabled

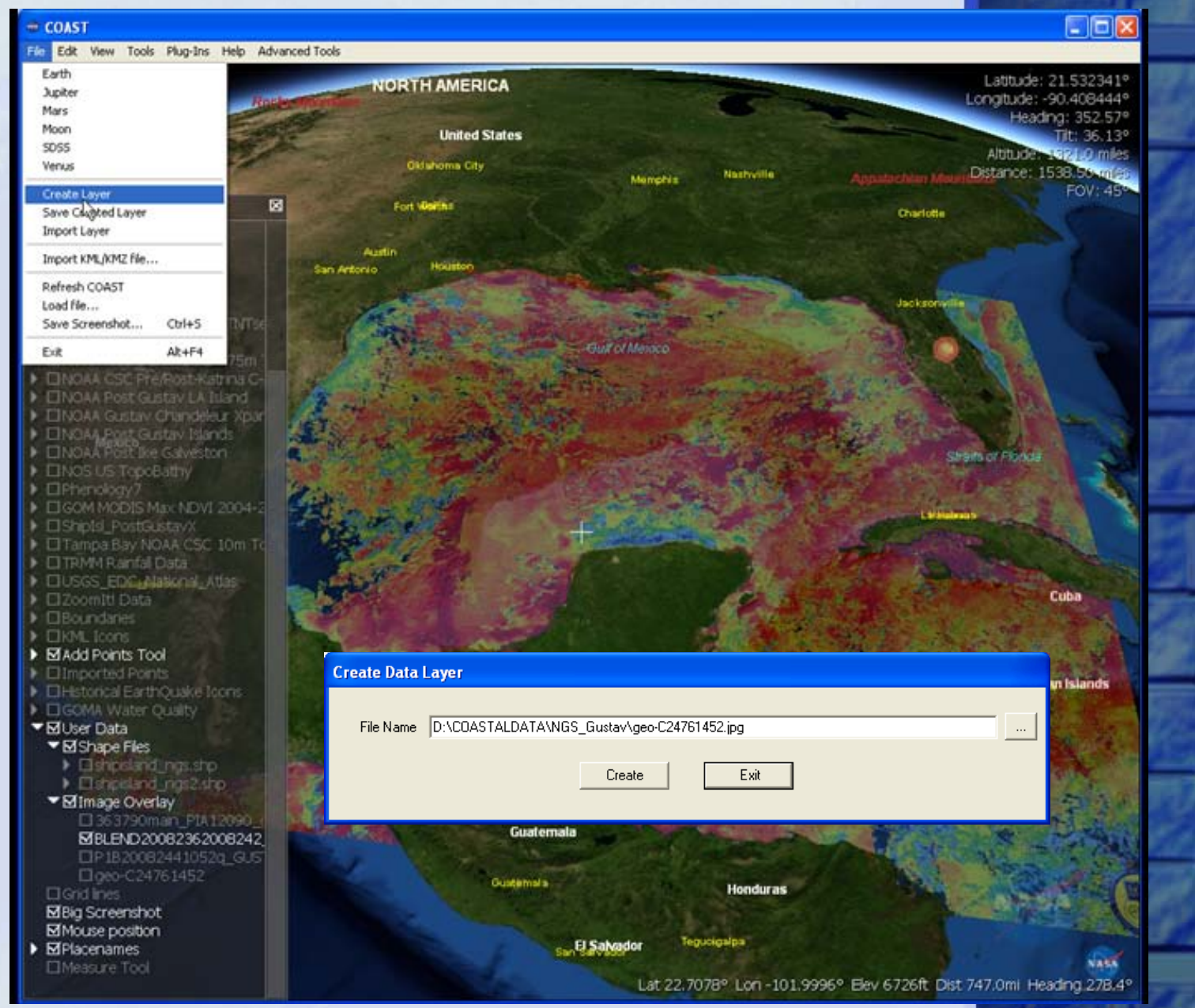

${ }^{1}$ Original contributed by Bjorn Reppen, included in WW $1.4 ;{ }^{2}$ limited use in WW $1.4 ;{ }^{3}$ inspired by Johann Zoehrer 


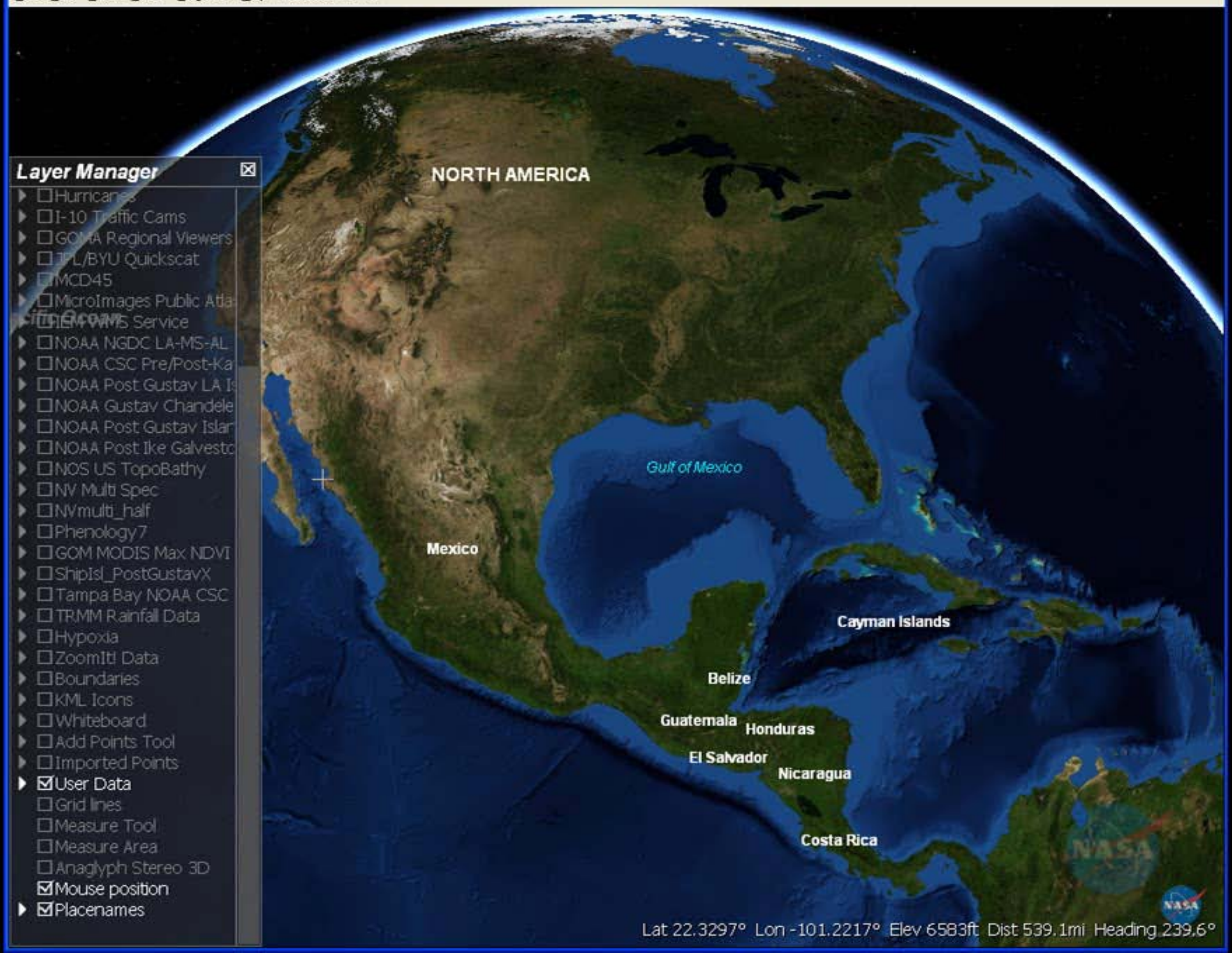


NORTH AMERICA

\section{Layer Manager}

凶

) प NOAA Post Gustav Islan

D. DNoAf Post ike Galveste

v G NOS US TopoBathy

1. anv Multi Spee

Y GNWmLiti half

- DPhenology?

- DGOM MODIS Max NOVI

- Dishipisl_PostGustavx

- DTampa Bay NOAA CSC

- DTRMM Rainfál Data

- Lihypoxia

- Gzoomiti Data

- DBoundaries

- DKML Icons

- $\square$ Whiteboard

D. $\square$ Add Points Tool

D Imported Points

- Vuser Data

- Ushape Files

D Gat.shp

- Dcatwigs84.shp

- $\square$ shipisland_ngsistip

- $\square$ shipisland_ngs 2.sh

- IImage overlay

口 363790 main_PIA1

DBLEND200823620

GMODIS 2008250

막1820082441052

অBLEND200820820

\section{口Grid lines}

ㅁMeasure Tool

口Measure Area

$\square$ Anaglyph Stereo 30

- Mouse position

- VPlacenames
United States

Fort Aptap

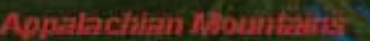

I

San Antonio
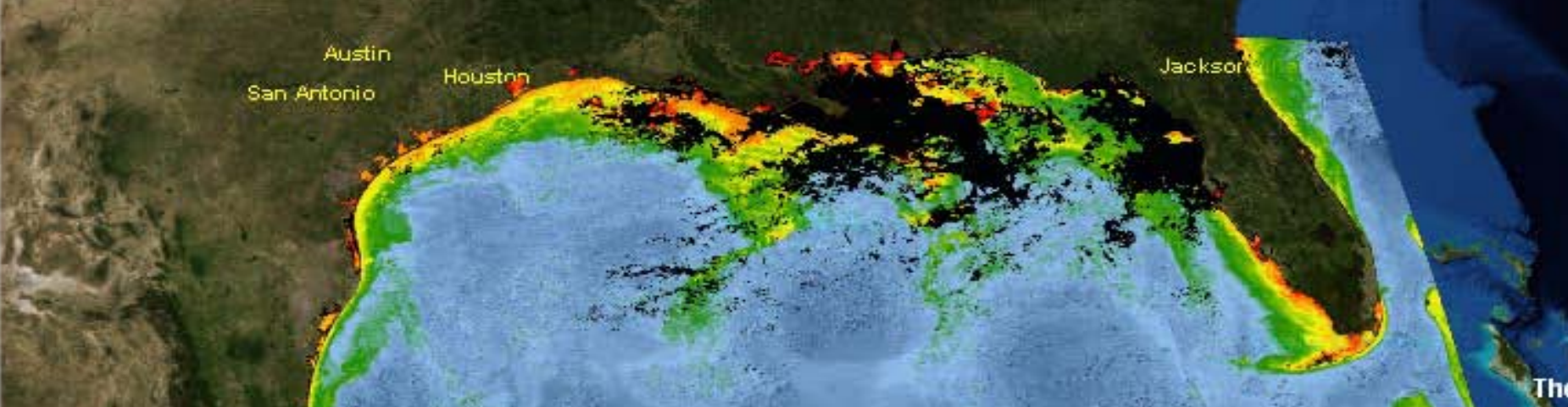

atweres lacksol ; $x+3 y=$

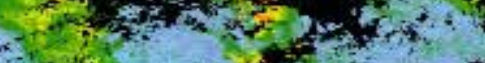

lexico

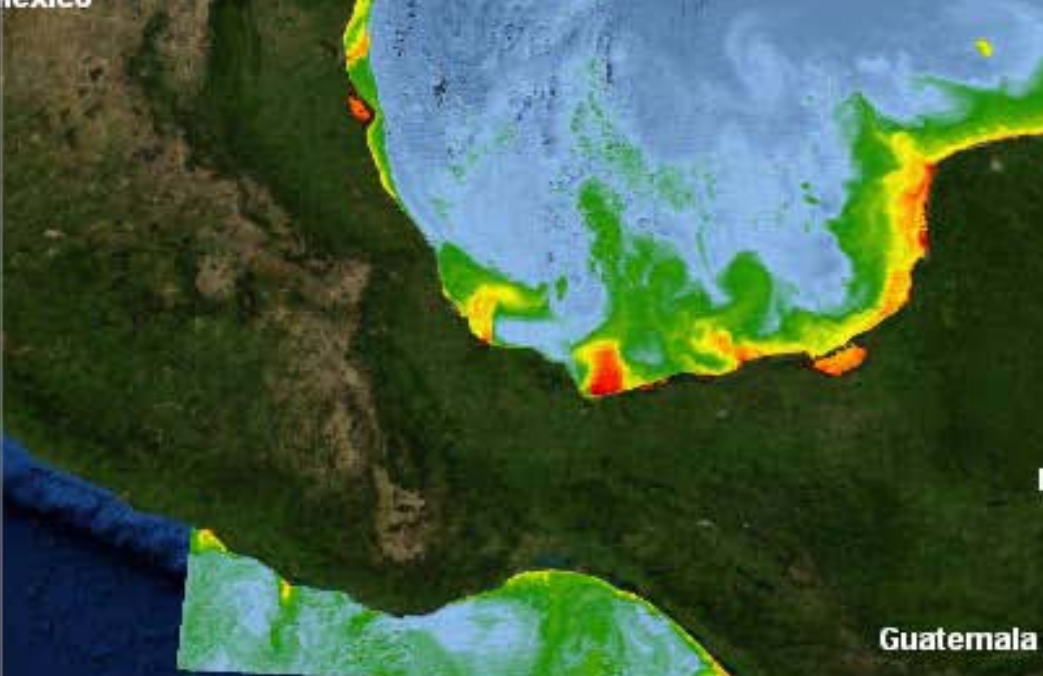

Guatemala

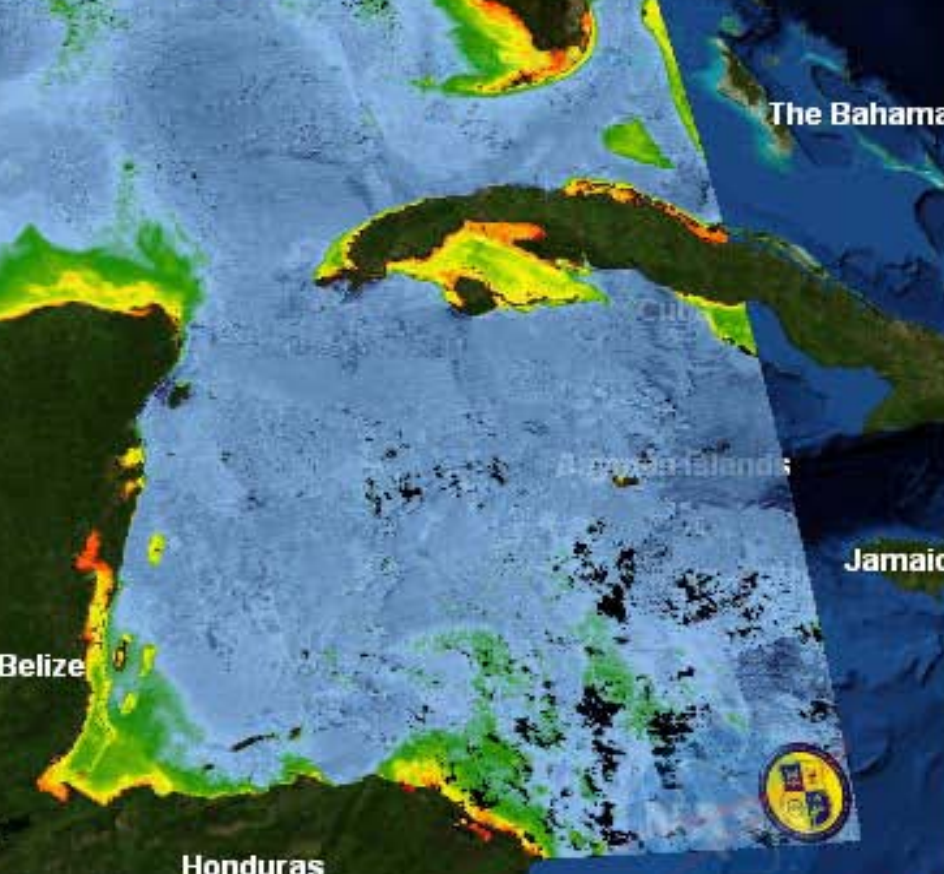




\section{COAST 2.0: Add Points Tool}
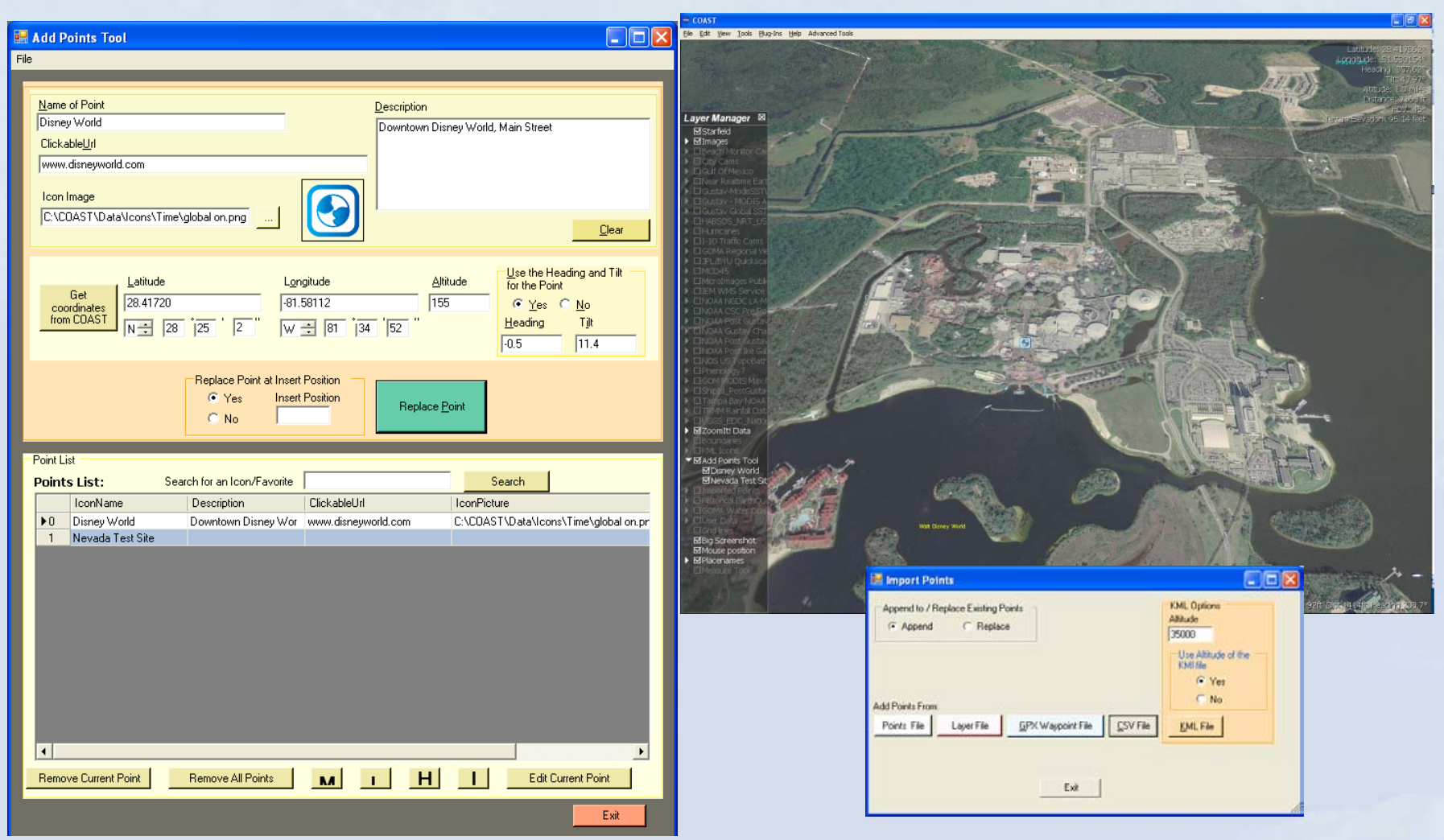

- User has the capability to directly digitize points onto the COAST interface, to add metadata and links directly, and to save the added points out to several shareable formats for use by others

- Users also have the option of typing in Web link addresses and location descriptions, and of selecting a custom icon to be used as a marker

- Points can also be edited and replaced as needed

- Points in TXT, CSV, COAST XML layer, or GPX format can also be added by an Import Points function located under the File menu

- Point set may be saved as a point TXT, CSV, or PRN file, or as a COAST-compatible XML layer

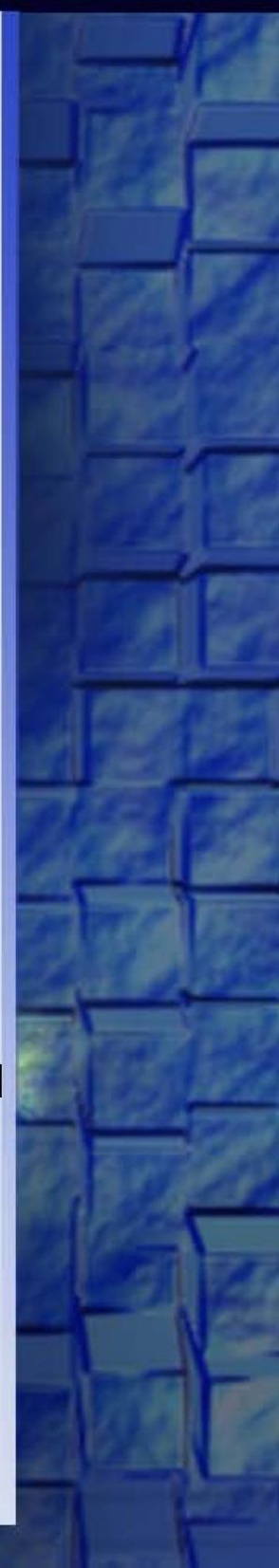




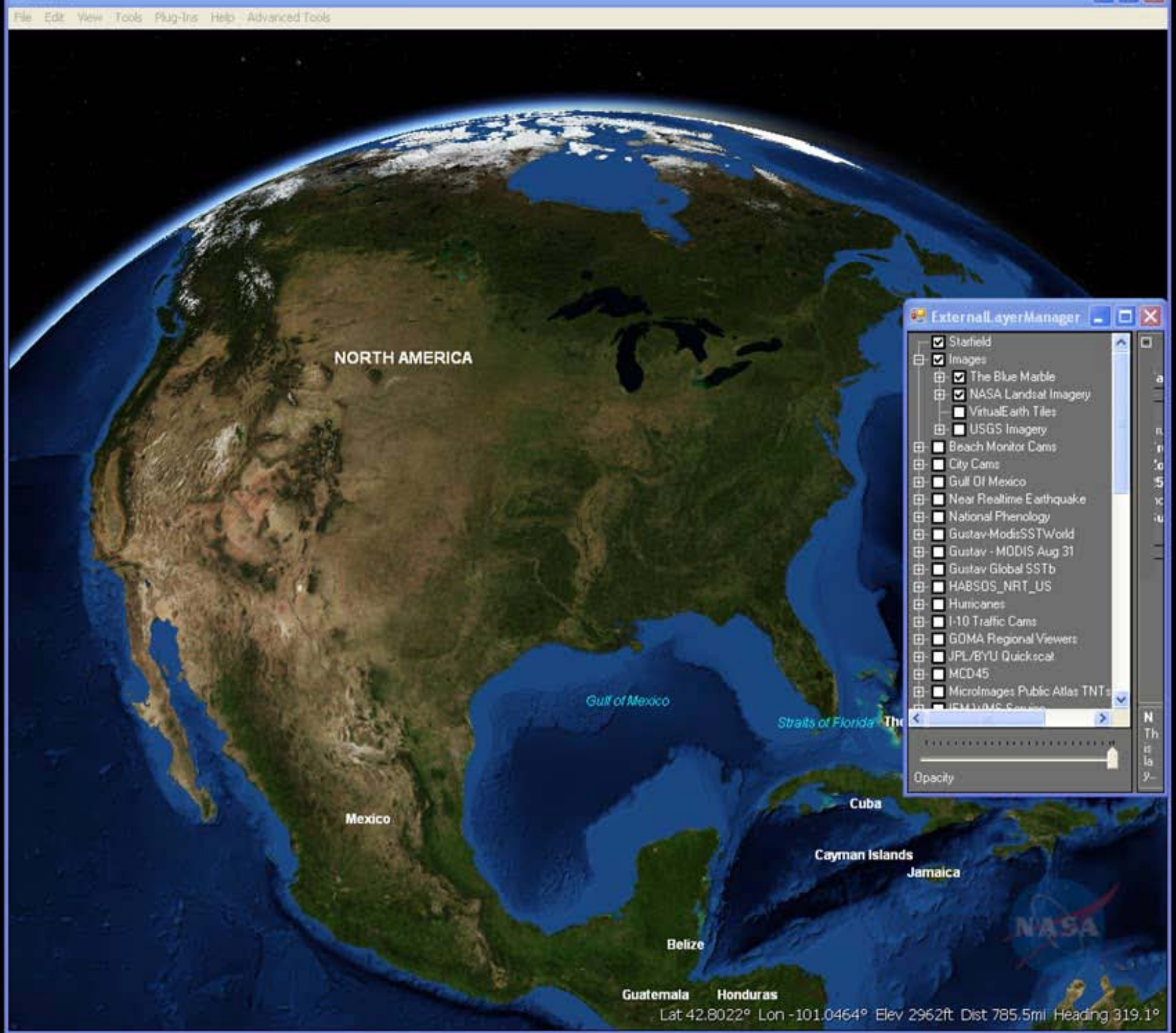


- 미 $x$

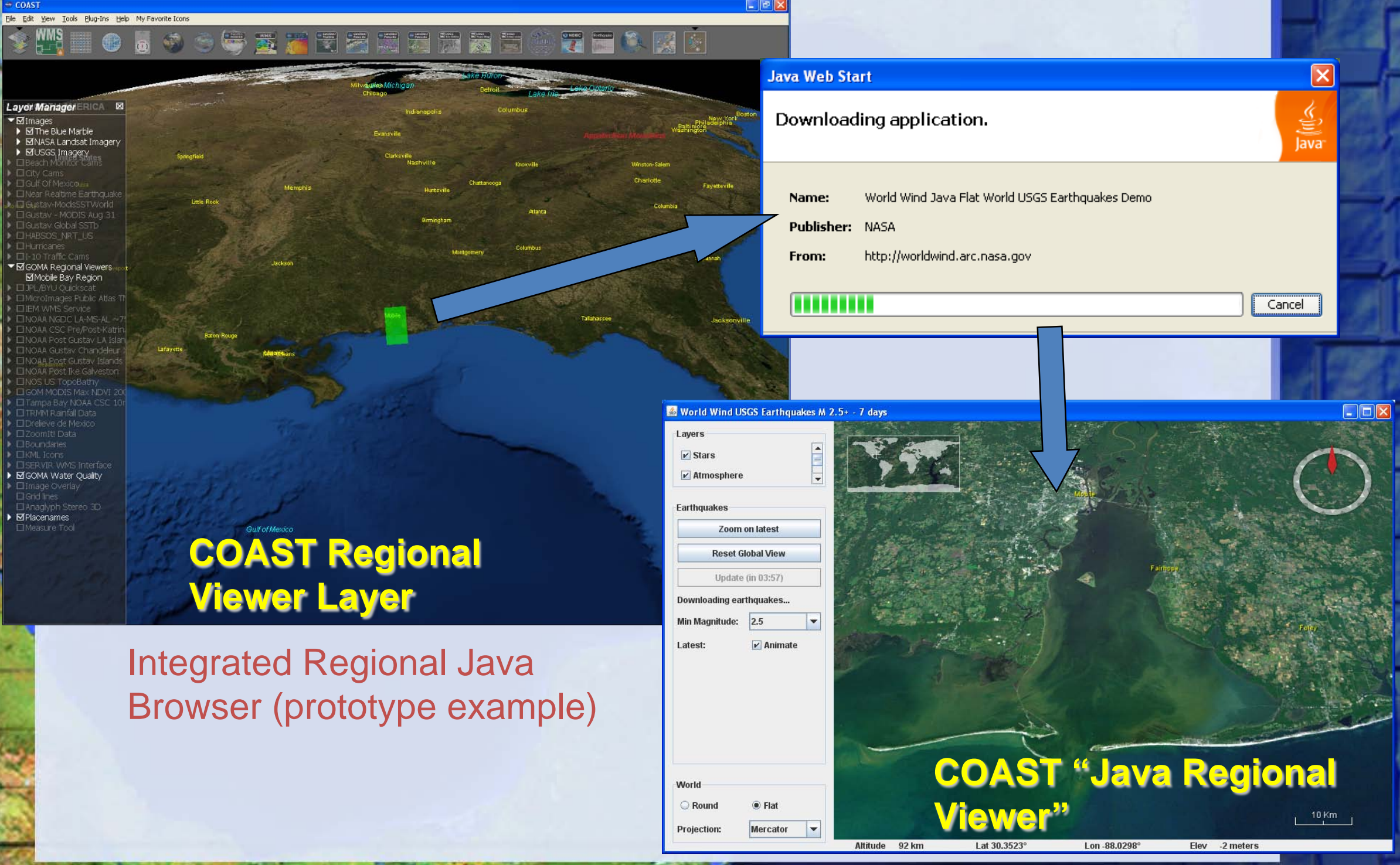


